\title{
High-dose Methotrexate and Rituximab Induction Regimen In Immunocompetent Patients With Primary CNS Lymphoma: A Retrospective Single- Center Study of Survival Predictors
}

\section{Andrew Burton DeAtkine ( $\nabla$ deatkine@uab.edu )}

University of Alabama Hospital: UAB Hospital https://orcid.org/0000-0003-3166-2448

\section{Moaaz Abdelrashid}

University of Alabama Hospital: UAB Hospital

\section{Zach Tucker}

University of Alabama Hospital: UAB Hospital James M. Markert

University of Alabama Hospital: UAB Hospital

Jinsuh Kim

University of Alabama Hospital: UAB Hospital

John B. Fiveash

University of Alabama Hospital: UAB Hospital

Robert A. Oster

University of Alabama Hospital: UAB Hospital

Mina Lobbous

University of Alabama Hospital: UAB Hospital

\section{Burt Nabors}

University of Alabama Hospital: UAB Hospital https://orcid.org/0000-0001-5926-2230

\section{Research Article}

Keywords: PCNSL, Methotrexate, Rituximab, HD-MTX, Outcomes, Primary CNS Lymphoma

Posted Date: January 14th, 2022

DOI: https://doi.org/10.21203/rs.3.rs-1250355/v1

License: (c) (1) This work is licensed under a Creative Commons Attribution 4.0 International License.

Read Full License 
Version of Record: A version of this preprint was published at Journal of Neuro-Oncology on April 20th, 2022. See the published version at https://doi.org/10.1007/s11060-022-04004-9. 


\section{Abstract}

\section{Purpose:}

Primary Central Nervous System Lymphoma (PCNSL) is an aggressive tumor that is confined to the CNS. Although the provision of high-dose methotrexate (HD-MTX) has remarkably improved outcomes in PCNSL patients, the optimal treatment regimens and standard MTX dose have been largely controversial. Herein, we sought to explore the impact of adjuvant Rituximab and different dosages of HD-MTX on survival outcomes of immunocompetent patients with PCNSL.

\section{Methods:}

In this study, we examined patients with PCNSL treated at a single NCl-designated comprehensive cancer center to evaluate their survival outcomes. We conducted a retrospective analysis of 51 immunocompetent patients with PCNSL who received their induction chemotherapy at the University of Alabama at Birmingham (UAB) between 2001 and 2019. Only adult patients with a confirmed diagnosis of PCNSL who had either HD-MTX alone or in combination with Rituximab were included. Patients' demographics, clinical characteristics, and survival data were collected and analyzed.

\section{Results:}

There is no significant difference in survival among patients who received MTX alone versus MTX plus Rituximab. Furthermore, lower doses of MTX were associated with worse survival outcomes; however, this difference in survival was not significant when adjusted to age.

\section{Conclusion:}

Our experience challenges the role of Rituximab in PCNSL during induction therapy. Our study also highlights the shorter survival in elderly patients with PCNSL which can be related, to some extent, to the relatively lower doses of HD-MTX. There is an unmet need to establish a consensus on the most effective upfront regimen in PCNSL through prospective studies.

\section{Introduction}

Primary Central Nervous System (CNS) Lymphoma (PCNSL) is a rare high-grade form of extra-nodal nonHodgkin lymphoma (NHL) that is confined to the CNS [1]. It comprises around $2 \%$ of primary CNS tumors in the US with an increased incidence in elderly and immunocompromised populations [2]. The tumor displays morphological patterns of diffuse large B-cell lymphoma (DLBCL) in the vast majority of cases $(>90 \%$ ) [3]. Typically, PCNSL invades the brain parenchyma, the vitreous body and nerves of the eye, the meninges, or the nerve roots of brain and spine [4]. Radiographically, it typically appears as a uniformly enhancing single brain lesion in immunocompetent patients with supratentorial predilection (87\%) on imaging [5]. The multitude of evolving therapeutic paradigms over the last decades have been linked to significant improvement of PCNSL overall survival (OS) and functional outcomes [6, 7]; nonetheless, the 
prognosis remains marginally satisfactory, wherein half of the patients relapse, and less than one third achieve a 5-year overall survival $[6,8]$.

The introduction of high-dose methotrexate (HD-MTX) chemotherapy, in particular, to PCNSL therapeutic armamentarium has led to an unequivocal, significant improvement in PCNSL prognosis and survival rates $[9,10]$. Although MTX is currently the single most effective chemotherapeutic agent for PCNSL and the backbone in the majority of induction regimens, its optimal dose and administration schedule have not been determined [11]. There is a growing consensus that MTX should be administered at a dose $\geq 3$ $\mathrm{g} / \mathrm{m}^{2}$ to achieve adequately active MTX concentrations in the brain tissues $[12,13]$. Recently, there has been an increasing trend of abandoning HD-MTX as monotherapy with growing evidence that combination therapy is more effective than HD-MTX alone [14-16]. Given that approximately $95 \%$ of PCNSLs are CD20-positive, it is hypothesized that rituximab, a CD20-targeted monoclonal antibody, may improve the response rate and long-term control of PCNSLs. Although rituximab has demonstrated significant improvement in OS in systemic B-cell lymphomas, the evidence of its effectiveness for PCNSL is still inconclusive and largely debated [17].

To date, induction therapy for PCNSL varies among different cancer centers [18]. This lack of consensus on optimal treatment regimens is a challenge to the neuro-oncology community and is largely attributed to the paucity of randomized controlled trials in PCNSL [19]. Therefore, further studies are warranted to address key questions, including the development of more effective and less toxic induction regimens and the selection of the most appropriate and effective consolidation approaches. More retrospective clinical studies can enrich the cumulative evidence on the disease outcomes and fill in the gaps created by lack of sufficient prospective data. Ideally, such studies should be performed at centers experienced with this type of brain cancer.

To approach some of these unanswered questions, the primary objective of this retrospective singlecenter study is to compare the clinical characteristics and overall survival of PCNSL patients initially treated with HD-MTX monotherapy to their counterparts who received an induction therapy with HD-MTX and rituximab. Furthermore, we explored the impact of different HD-MTX dosage regimens on survival.

\section{Methods}

\section{Study design and data collection}

In this single-center, retrospective study, we analyzed all patients with newly diagnosed PCNSL treated consecutively in our institution between February 1, 2001, and April 23, 2019. Patients included were histologically diagnosed of primary DLBCL of the CNS who had received an upfront treatment with either HD-MTX alone or in combination with rituximab. Immunocompromised patients (e.g., HIV, Posttransplant), and patients with NHL manifestations outside the CNS or with secondary CNS involvement were excluded from the study. Fifty-one patients met these criteria and were selected for data collection. Data were collected by reviewing patients' medical records. Race, gender, age at PCNSL diagnosis, 
method of diagnosis (brain biopsy or CSF study), induction treatment type (HD-MTX or HD-MTX + rituximab), mean dose of MTX per infusion, and survival status were gathered from patients' charts. If the patients' survival status and dates of death (if deceased) were not available in their medical records, this data was gathered from publicly available records. The duration of overall survival-measured as the time between pathological diagnosis and either the date of death or the date of the most recent recorded patient contact at UAB which was calculated for each patient and served as the primary outcome variable of interest for the study.

\section{Treatment protocol}

At our institution, the current treatment protocol for PCNSL is based on the report of New Approaches to Brain Tumor Therapy (NABTT) CNS Consortium, administrating an initial dose of MTX ( $8 \mathrm{~g} / \mathrm{m} 2)$ every two weeks for a maximum of six cycles. Doses are adjusted according to renal function and drug tolerance, and weekly RTX (375 mg/m2/dose) was included at the treating physician's discretion [26].

\section{Statistical Analysis}

Descriptive statistics were determined for all the study variables, including age at diagnosis, treatment group (HD-MTX only and HD-MTX + Rituximab), MTX dose group (low dose: $<5.6 \mathrm{gm} / \mathrm{m}^{2}$; high dose: $\geq$ $\left.5.6 \mathrm{gm} / \mathrm{m}^{2}\right)$, mean MTX dose, gender, and race. The dose threshold $\left(5.6 \mathrm{gm} / \mathrm{m}^{2}\right)$ was identified as the second quartile (Q2) value which equally splits the HD-MTX recommended dosage range for the PCNSL (3-8 $\left.\mathrm{g} / \mathrm{m}^{2}\right)$ into two halves. Comparisons of proportions for gender and race between the treatment groups and between the dose groups were performed using the chi-square test, or Fisher's exact test when the assumptions for the chi-square test were not tenable. Age at diagnosis and MTX dose were examined for normality using box plots, stem and leaf plots, and normal probability plots; since these variables were determined to be non-normally distributed, comparisons of means between the treatment groups and between the dose groups were performed using the Wilcoxon rank-sum test. Correlations between variables were examined using Spearman correlation analysis. Kaplan-Meier plots and the log-rank test were used to compare survival curves. Individual and multiple potential predictors of patient survival were assessed using Cox proportional hazards models (Cox regression analysis). Statistical tests were twosided and were performed using a significance level of $5 \%$. Statistical analyses were performed using SAS software (version 9.4; Cary, NC). One Asian patient was classified as White for purposes of statistical analysis; however, all analyses were repeated excluding this patient, and the results obtained were nearly identical to those obtained when all patients were included (data not shown).

\section{Results}

\section{Descriptive Analysis of Demographics and Clinical Characteristics}

Demographic and clinical characteristics for the cohort sample and for the therapeutic arms are summarized in Table 1 and S. Table1. A total of 51 patients were included in the analysis, of which $63 \%$ were male and $37 \%$ were female, and $92 \%$ were White and $8 \%$ were African American. Males and females 
were equally distributed in the lower HD-MTX arm, whereas proportions of males (68.6\%) were much higher that females' (31.4\%) in the higher dosage group. Overall, the mean age at diagnosis was 61.5 years (SD $=14.1$ years) and the mean MTX dose was $6.2 \mathrm{gm} / \mathrm{m}^{2}\left(\mathrm{SD}=1.7 \mathrm{gm} / \mathrm{m}^{2}\right)$.Nonetheless, when stratified by dosage group, the mean age of patients receiving lower doses of MTX was strikingly higher than the mean age of their counterparts in the higher dosage group $(p<0.001)$. There were no statistically significant differences between the dosage groups for gender $(p=0.203)$, race $(p=1.0)$, or induction regimen $(p=0.742)$. There were no statistically significant differences between the two treatment groups (MTX only and MTX plus Rituximab) for age at diagnosis $(p=0.73)$, MTX dose $(p=0.87)$, gender $(p=0.43)$, or race $(p=0.12)(S$. Table1).

\section{Univariate Survival Analyses}

Kaplan-Meier survival analysis showed no significant difference in survival between the two induction regimens $(p=0.99)$, indicating that adding rituximab to treatment regimen had not produced a difference in patient survival (Figure 1.A). On the other hand, there was a significant improvement in survival associated with the higher MTX dosage group $(p=0.017)$, suggesting that the higher the methotrexate doses the more robust the therapeutic response elicited and, subsequently, the longer the survival times in PCNSL patients.

\section{Multivariate Survival Analyses}

We then sought to adjust our analysis to eliminate any potentially confounding factors. For this purpose, we constructed proportional hazard Cox Regression prediction models for age at diagnosis, treatment group, MTX dose group, and mean MTX dose (Table 2). The first four models examined whether these variables, without adjustment for other variables, predicted survival. Age at diagnosis [HR=1.053 ( $95 \% \mathrm{Cl}$ : 1.016-1.092), $p=0.006$ ], MTX dose group [HR=0.364 (95\% Cl: 0.154-0.863), $p=0.022$ ], and mean MTX dose [HR=0.680 (95\% Cl: 0.530-0.872), $p=0.002]$ were determined to be significant individual predictors of survival while treatment group was not. Indeed, age at diagnosis was inversely correlated to mean MTX dose $\left(r_{s}=-0.626, p<0.001\right)$. It was imperative to explore whether the significant survival benefit in the higher MTX dose group could be attributed to the confounding effect from age differences at diagnosis or to the the average methotrexate doses and induction regimen in both groups. Therefore, we included age at diagnosis as a covariate in models with treatment group, MTX dose group, and mean MTX dose (models 5-7). In model 5, treatment group was not a significant predictor of overall survival, and in model 6, MTX dose group was not a significant predictor of survival; however, age at diagnosis remained a significant predictor of survival in both models, with higher ages being associated with shorter survival. Lastly, in model 7, neither mean MTX dose nor age at diagnosis were significant predictors of survival which further confirms age at diagnosis as a confounding factor rather than being an effect modifier.

\section{Discussion}


Herein, we present our institution's experience with induction therapy of PCNSL. This retrospective study compares clinical outcomes in immunocompetent PCNSL patients treated with either HD-MTX induction monotherapy or a combination regimen of HD-MTX plus rituximab. Additionally, we explore the association between overall survival and methotrexate dosage. In this study, we evaluated 51 patients with PCNSL who were treated at the UAB O'Neal Comprehensive Cancer Center between 2001 to 2019. Patients were stratified by age, treatment regimen, average dose, dosing group, and age. Our results demonstrated no additional survival benefits associated with rituximab as an adjuvant therapeutic agent to the HD-MTX induction chemotherapy. Furthermore, higher doses of MTX were associated with superior survival outcomes; however, this survival benefit was not significant when adjusted for age. The latter finding sheds light on the dismal clinical outcomes depicted in the growing elderly population with PCNSL which can be, at least partly, attributed to receiving relatively lower HD-MTX doses.

Management for PCNSL has evolved over the past few decades; however, to date, there is a general lack of consensus about the optimal first-line chemotherapy regimen, and, therefore, the clinical practice varies across institutions [20]. Whole-brain-radiation-therapy (WBRT) constituted the main standard of therapy for newly diagnosed PCNSL patients until the 1980s when trials emerged investigating multimodal approaches, combining chemotherapy with radiation therapy [10,21]. The combination of cyclophosphamide, doxorubicin, vincristine, and prednisone (CHOP) has been an effective regimen for systemic non-Hodgkin lymphoma but not in PCNSL due to its inability to cross the blood brain barrier (BBB) [22-24]. Likewise, other combination regimens of carmustine, etoposide, cytarabine, and melphalan (BEAM) were found to be ineffective [25]. HD-MTX with rapid infusion rates demonstrated the most beneficial clinical outcomes, likely due to its superior capacity to cross the BBB [26, 27]. HD-MTX in combination with WBRT significantly improved outcomes with a median OS of 30 to 60 months compared to WBRT alone (12 to 18 months) [28, 29]. However, the neurotoxicity associated with high doses of radiation is a main limiting factor; moreover, in 2010 , a phase III randomized study comparing HD-MTX with or without WBRT did not demonstrate a statistically significant difference in overall survival [30]. Subsequently, WBRT has largely been avoided during induction therapy but is still being recommended by some authorities as a standard-of-care in consolidation or salvage therapy [31]. From a neurosurgical perspective, the diffusely infiltrating growth of PCNSL usually restricts the role of surgical resection to stereotactic biopsy. Additionally, previous retrospective studies have failed to demonstrate improvement in survival following gross total or subtotal resection of PCNSLs [32]. Currently, there is not sufficient evidence to support the recommendation for an aggressive surgical approach in PCNSL.

Most upfront treatment protocols combine HD-MTX with a variety of other chemotherapeutic agents, and MTX monotherapy has become less popular $[18,33]$. Some retrospective studies suggested that rituximab improves both overall and progression-free survival when combined with MTX [34, 35]. Although the emerging results from a few single-arm, phase II trials have also supported the use of HDMTX, with or without high-dose cytarabine, plus an alkylating agent and rituximab as induction regimen for $\leq 70$-year-old PCNSL patients, these trials have not shown a distinct therapeutic effect attributed to each drug (i.e., rituximab or alkylating agent) separately to draw a conclusion upon $[15,16,36]$. Furthermore, the role of rituximab in induction regimen of PCNSL has been recently challenged by a 
randomized phase II trial of the Dutch-Belgian Cooperative Trial Group for Hematology Oncology and the Australasian Leukaemia and Lymphoma Group [37]. Given this uncertainty on its positive effects, the decision to add rituximab into PCNSL treatment regimen should be carefully weighed against the proposed increase in cost of treatment as well as the potential adverse outcomes of its administration.

Since its provision, HD-MTX has been the single most effective chemotherapeutic agent for PCNSL and the backbone in the majority of induction regimens [26, 27]. However, the optimum HD-MTX dose and its ideal administration schedule are still controversial $[11,13]$. Patients with inadequate renal function often receive non-MTX-based chemotherapy with or without Rituximab including high-dose cytarabine or temozolomide; those with mild or moderate renal insufficiency may receive HD-MTX but at lower doses adjusted by creatinine clearance [20,36]. Of particular importance, PCNSL incidence has been steadily increasing in the elderly population [38,39]. This group of patients does not often tolerate strong genotoxic irradiation or high-dose chemotherapy (HDC)-based strategies well [9]. Our study reemphasizes the current challenges in treating elderly patient with PCNSL wherein the higher age at time of diagnosis was associated with receiving relatively lower doses of HD-MTX. Our results further suggest that maintaining a higher dose, as possible, of HD-MTX can result in improving clinical response in this population. Similarly, a recent cohort by Li et al has reported that a higher MTX dose (HD-MTX dose of 8 $\mathrm{g} / \mathrm{m} 2$ ) is significantly associated with better clinical response rates and higher progression free survival in managing PCNSL [40]. An ongoing study using scheduled glucarpidase with HD-MTX may facilitate administering higher doses of MTX while minimizing side effects that may result from HD-MTX [41]. The increasing incidence of elderly PCNSL demands trials specifically targeting this patient population to facilitate delivering higher therapeutic doses of methotrexate in elderly patients without compromising their renal function.

Our study has intrinsic limitations given that it is a retrospective, single-institution analysis. These include suboptimal matching of the 2 patient cohorts because patients were not prospectively assigned to the different treatment arms using prognostic factors for randomization and the fact that the radiology review was done in a nonblinded manner. Considering the rarity of this disease, this study provides a relatively substantial sample size from a single institution.

\section{Declarations}

Funding: The authors received no funding during the preparation of this manuscript.

Conflicts of interest/Competing interests: None of the authors have conflicts of interests or relevant financial disclosures.

Author Contributions: Andrew B. DeAtkine, Moaaz Abdelrashid, Mina Lobbous, and L. Burt Nabors contributed to the study conception and design. Material preparation and data collection were performed by Andrew B. DeAtkine and Zach Tucker. Statistical analysis, tables, and figures were performed and generated by Robert A. Oster. The first draft of the manuscript was written by Andrew B. DeAtkine, Mina 
Lobbous, Moaaz Abdelrashid, Robert A. Oster, and Zach Tucker. All authors commented on previous versions of the manuscript. All authors read and approved the final manuscript.

Data Availability: The data generated and analyzed during the current study are available from the corresponding author upon reasonable request.

Ethics Approval: This is a retrospective study, and the UAB Institutional Review Board has confirmed that no ethical approval is required.

Consent to participate: This is a retrospective study, and subjects' consent to participate was not required.

Consent for publication: All authors have reviewed and approved this manuscript for submission.

\section{References}

1. Gerstner ER, Batchelor TT (2010) Primary central nervous system lymphoma. Arch Neurol 67: 291297 doi:10.1001/archneurol.2010.3

2. Ostrom QT, Gittleman H, Xu J, Kromer C, Wolinsky Y, Kruchko C, Barnholtz-Sloan JS (2016) CBTRUS Statistical Report: Primary Brain and Other Central Nervous System Tumors Diagnosed in the United States in 2009-2013. Neuro Oncol 18: v1-v75 doi:10.1093/neuonc/now207

3. Montesinos-Rongen M, Brunn A, Bentink S, Basso K, Lim WK, Klapper W, Schaller C, Reifenberger G, Rubenstein J, Wiestler OD, Spang R, Dalla-Favera R, Siebert R, Deckert M (2008) Gene expression profiling suggests primary central nervous system lymphomas to be derived from a late germinal center B cell. Leukemia 22: 400-405 doi:10.1038/sj.leu.2405019

4. Rubenstein J, Ferreri AJ, Pittaluga S (2008) Primary lymphoma of the central nervous system: epidemiology, pathology and current approaches to diagnosis, prognosis and treatment. Leukemia \& lymphoma 49: 43-51

5. Kuker W, Nagele T, Korfel A, Heckl S, Thiel E, Bamberg M, Weller M, Herrlinger U (2005) Primary central nervous system lymphomas (PCNSL): MRI features at presentation in 100 patients. $J$ Neurooncol 72: 169-177 doi:10.1007/s11060-004-3390-7

6. Grommes C, DeAngelis LM (2017) Primary CNS lymphoma. Journal of Clinical Oncology 35: 2410

7. Hoang-Xuan K, Bessell E, Bromberg J, Hottinger AF, Preusser M, Ruda R, Schlegel U, Siegal T, Soussain C, Abacioglu U, Cassoux N, Deckert M, Dirven CM, Ferreri AJ, Graus F, Henriksson R, Herrlinger U, Taphoorn M, Soffietti R, Weller M, European Association for Neuro-Oncology Task Force on Primary CNSL (2015) Diagnosis and treatment of primary CNS lymphoma in immunocompetent patients: guidelines from the European Association for Neuro-Oncology. Lancet Oncol 16: e322-332 doi:10.1016/S1470-2045(15)00076-5

8. Korfel A, Schlegel U (2013) Diagnosis and treatment of primary CNS lymphoma. Nature Reviews Neurology 9: 317-327 
9. Fritsch K, Kasenda B, Schorb E, Hau P, Bloehdorn J, Mohle R, Low S, Binder M, Atta J, Keller U, Wolf HH, Krause SW, Hess G, Naumann R, Sasse S, Hirt C, Lamprecht M, Martens U, Morgner A, Panse J, Frickhofen N, Roth A, Hader C, Deckert M, Fricker H, lhorst G, Finke J, Illerhaus G (2017) High-dose methotrexate-based immuno-chemotherapy for elderly primary CNS lymphoma patients (PRIMAIN study). Leukemia 31: 846-852 doi:10.1038/leu.2016.334

10. Grommes C, DeAngelis LM (2017) Primary CNS Lymphoma. J Clin Oncol 35: 2410-2418 doi:10.1200/JC0.2017.72.7602

11. Joerger M, Ferreri AJ, Krahenbuhl S, Schellens JH, Cerny T, Zucca E, Huitema AD (2012) Dosing algorithm to target a predefined AUC in patients with primary central nervous system lymphoma receiving high dose methotrexate. Br J Clin Pharmacol 73: 240-247 doi:10.1111/j.13652125.2011.04084.x

12. Ferreri AJ, Guerra E, Regazzi M, Pasini F, Ambrosetti A, Pivnik A, Gubkin A, Calderoni A, Spina M, Brandes A, Ferrarese F, Rognone A, Govi S, Dell'Oro S, Locatelli M, Villa E, Reni M (2004) Area under the curve of methotrexate and creatinine clearance are outcome-determining factors in primary CNS lymphomas. Br J Cancer 90: 353-358 doi:10.1038/sj.bjc.6601472

13. Joerger M, Huitema AD, Illerhaus G, Ferreri AJ (2012) Rational administration schedule for high-dose methotrexate in patients with primary central nervous system lymphoma. Leuk Lymphoma 53: 18671875 doi:10.3109/10428194.2012.676177

14. Ferreri AJM (2017) Therapy of primary CNS lymphoma: role of intensity, radiation, and novel agents. Hematology Am Soc Hematol Educ Program 2017: 565-577 doi:10.1182/asheducation-2017.1.565

15. Ferreri AJ, Cwynarski K, Pulczynski E, Ponzoni M, Deckert M, Politi LS, Torri V, Fox CP, La Rosée P, Schorb E (2016) Chemoimmunotherapy with methotrexate, cytarabine, thiotepa, and rituximab (MATRix regimen) in patients with primary CNS lymphoma: results of the first randomisation of the International Extranodal Lymphoma Study Group-32 (IELSG32) phase 2 trial. The Lancet Haematology 3: e217-e227

16. Ferreri AJ, Reni M, Foppoli M, Martelli M, Pangalis GA, Frezzato M, Cabras MG, Fabbri A, Corazzelli G, Ilariucci $F$ (2009) High-dose cytarabine plus high-dose methotrexate versus high-dose methotrexate alone in patients with primary CNS lymphoma: a randomised phase 2 trial. The Lancet 374: 15121520

17. Van Dijck R, Doorduijn JK, Bromberg JEC (2021) The Role of Rituximab in the Treatment of Primary Central Nervous System Lymphoma. Cancers (Basel) 13 doi:10.3390/cancers13081920

18. Yu J, Du H, Ye X, Zhang L, Xiao H (2021) High-dose methotrexate-based regimens and post-remission consolidation for treatment of newly diagnosed primary CNS lymphoma: meta-analysis of clinical trials. Sci Rep 11: 2125 doi:10.1038/s41598-020-80724-0

19. Schaff LR, Ambady P, Doolittle ND, Grommes C (2021) Primary central nervous system lymphoma: a narrative review of ongoing clinical trials and goals for future studies. Ann Lymphoma 5 doi:10.21037/aol-20-47 
20. Grommes C, Rubenstein JL, DeAngelis LM, Ferreri AJM, Batchelor TT (2019) Comprehensive approach to diagnosis and treatment of newly diagnosed primary CNS lymphoma. Neuro Oncol 21: 296-305 doi:10.1093/neuonc/noy192

21. Nelson DF, Martz KL, Bonner H, Nelson JS, Newall J, Kerman HD, Thomson JW, Murray KJ (1992) Non-Hodgkin's lymphoma of the brain: can high dose, large volume radiation therapy improve survival? Report on a prospective trial by the Radiation Therapy Oncology Group (RTOG): RTOG 8315. Int J Radiat Oncol Biol Phys 23: 9-17 doi:10.1016/0360-3016(92)90538-s

22. O'Neill BP, Wang CH, O'Fallon JR, Colgan JD, Earle JD, Krigel RL, Brown LD, McGinnis WL (1999) Primary central nervous system non-Hodgkin's lymphoma (PCNSL): survival advantages with combined initial therapy? A final report of the North Central Cancer Treatment Group (NCCTG) Study 86-72-52. Int J Radiat Oncol Biol Phys 43: 559-563 doi:10.1016/s0360-3016(98)00450-7

23. Schultz C, Scott C, Sherman W, Donahue B, Fields J, Murray K, Fisher B, Abrams R, Meis-Kindblom J (1996) Preirradiation chemotherapy with cyclophosphamide, doxorubicin, vincristine, and dexamethasone for primary CNS lymphomas: initial report of radiation therapy oncology group protocol 88-06. J Clin Oncol 14: 556-564 doi:10.1200/JC0.1996.14.2.556

24. Mead GM, Bleehen NM, Gregor A, Bullimore J, Shirley D, Rampling RP, Trevor J, Glaser MG, Lantos P, Ironside JW, Moss TH, Brada M, Whaley JB, Stenning SP (2000) A medical research council randomized trial in patients with primary cerebral non-Hodgkin lymphoma: cerebral radiotherapy with and without cyclophosphamide, doxorubicin, vincristine, and prednisone chemotherapy. Cancer 89: $1359-1370$

25. Colombat P, Lemevel A, Bertrand P, Delwail V, Rachieru P, Brion A, Berthou C, Bay JO, Delepine R, Desablens B, Camilleri-Broet S, Linassier C, Lamy T (2006) High-dose chemotherapy with autologous stem cell transplantation as first-line therapy for primary CNS lymphoma in patients younger than 60 years: a multicenter phase II study of the GOELAMS group. Bone Marrow Transplant 38: 417-420 doi:10.1038/sj.bmt.1705452

26. Batchelor T, Carson K, O'Neill A, Grossman SA, Alavi J, New P, Hochberg F, Priet R (2003) Treatment of primary CNS lymphoma with methotrexate and deferred radiotherapy: a report of NABTT 96-07. J Clin Oncol 21: 1044-1049 doi:10.1200/JC0.2003.03.036

27. Gerstner ER, Carson KA, Grossman SA, Batchelor TT (2008) Long-term outcome in PCNSL patients treated with high-dose methotrexate and deferred radiation. Neurology 70: 401-402 doi:10.1212/01.wnl.0000300671.37279.0e

28. Poortmans PM, Kluin-Nelemans HC, Haaxma-Reiche $H$, Van't Veer $M$, Hansen M, Soubeyran $P$, Taphoorn M, Thomas J, Van den Bent M, Fickers M, Van Imhoff G, Rozewicz C, Teodorovic I, van Glabbeke M, European Organization for R, Treatment of Cancer Lymphoma G (2003) High-dose methotrexate-based chemotherapy followed by consolidating radiotherapy in non-AIDS-related primary central nervous system lymphoma: European Organization for Research and Treatment of Cancer Lymphoma Group Phase II Trial 20962. J Clin Oncol 21: 4483-4488 doi:10.1200/JC0.2003.03.108 
29. DeAngelis LM, Seiferheld W, Schold SC, Fisher B, Schultz CJ, Radiation Therapy Oncology Group S (2002) Combination chemotherapy and radiotherapy for primary central nervous system lymphoma: Radiation Therapy Oncology Group Study 93-10. J Clin Oncol 20: 4643-4648 doi:10.1200/JC0.2002.11.013

30. Thiel E, Korfel A, Martus P, Kanz L, Griesinger F, Rauch M, Roth A, Hertenstein B, von Toll T, Hundsberger T, Mergenthaler HG, Leithauser M, Birnbaum T, Fischer L, Jahnke K, Herrlinger U, Plasswilm L, Nagele T, Pietsch T, Bamberg M, Weller M (2010) High-dose methotrexate with or without whole brain radiotherapy for primary CNS lymphoma (G-PCNSL-SG-1): a phase 3, randomised, non-inferiority trial. Lancet Oncol 11: 1036-1047 doi:10.1016/S1470-2045(10)70229-1

31. DeAngelis LM (2011) Radiotherapy: has the role of WBRT in primary CNS lymphoma been settled? Nat Rev Clin Oncol 8: 196-198 doi:10.1038/nrclinonc.2011.18

32. Jahr G, Da Broi M, Holte H, Jr., Beiske K, Meling TR (2018) The role of surgery in intracranial PCNSL. Neurosurg Rev 41: 1037-1044 doi:10.1007/s10143-018-0946-0

33. Omuro A, Chinot O, Taillandier L, Ghesquieres H, Soussain C, Delwail V, Lamy T, Gressin R, Choquet S, Soubeyran P (2015) Methotrexate and temozolomide versus methotrexate, procarbazine, vincristine, and cytarabine for primary CNS lymphoma in an elderly population: an intergroup ANOCEFGOELAMS randomised phase 2 trial. The Lancet Haematology 2: e251-e259

34. Gregory G, Arumugaswamy A, Leung T, Chan KL, Abikhair M, Tam C, Bajel A, Cher L, Grigg A, Ritchie D, Opat $S$ (2013) Rituximab is associated with improved survival for aggressive B cell CNS lymphoma. Neuro Oncol 15: 1068-1073 doi:10.1093/neuonc/not032

35. Holdhoff M, Ambady P, Abdelaziz A, Sarai G, Bonekamp D, Blakeley J, Grossman SA, Ye X (2014) High-dose methotrexate with or without rituximab in newly diagnosed primary CNS lymphoma. Neurology 83: 235-239 doi:10.1212/WNL.0000000000000593

36. Ferreri AJM, Holdhoff M, Nayak L, Rubenstein JL (2019) Evolving Treatments for Primary Central Nervous System Lymphoma. Am Soc Clin Oncol Educ Book 39: 454-466 doi:10.1200/EDBK_242547

37. Bromberg JE, Issa S, Bakunina K, Minnema MC, Seute T, Durian M, Cull G, Schouten HC, Stevens WB, Zijlstra JM (2019) Rituximab in patients with primary CNS lymphoma (HOVON 105/ALLG NHL 24): a randomised, open-label, phase 3 intergroup study. The Lancet Oncology 20: 216-228

38. O'Neill BP, Decker PA, Tieu C, Cerhan JR (2013) The changing incidence of primary central nervous system lymphoma is driven primarily by the changing incidence in young and middle-aged men and differs from time trends in systemic diffuse large B-cell non-Hodgkin's lymphoma. Am J Hematol 88: 997-1000 doi:10.1002/ajh.23551

39. Villano J, Koshy M, Shaikh H, Dolecek T, McCarthy B (2011) Age, gender, and racial differences in incidence and survival in primary CNS lymphoma. British journal of cancer 105: 1414-1418

40. Li Q, Ma J, Ma Y, Lin Z, Kang H, Chen B (2021) Improvement of outcomes of an escalated high-dose methotrexate-based regimen for patients with newly diagnosed primary central nervous system lymphoma: a real-world cohort study. Cancer Manag Res 13: 6115-6122 doi:10.2147/CMAR.S322467 
41. Schaff L, Lobbous M, Sener U, et al. CTNI-61. PILOT STUDY OF REPEATED PLANNED GLUCARPIDASE FOLLOWING HIGH DOSE METHOTREXATE (HD-MTX) IN CNS LYMPHOMA (CNSL) Neuro-oncology. 2020 Nov;22(Suppl 2):ii56-ii56. PMCID: PMC7651121.

\section{Tables}

Table 1. Demographic and clinical characteristics 


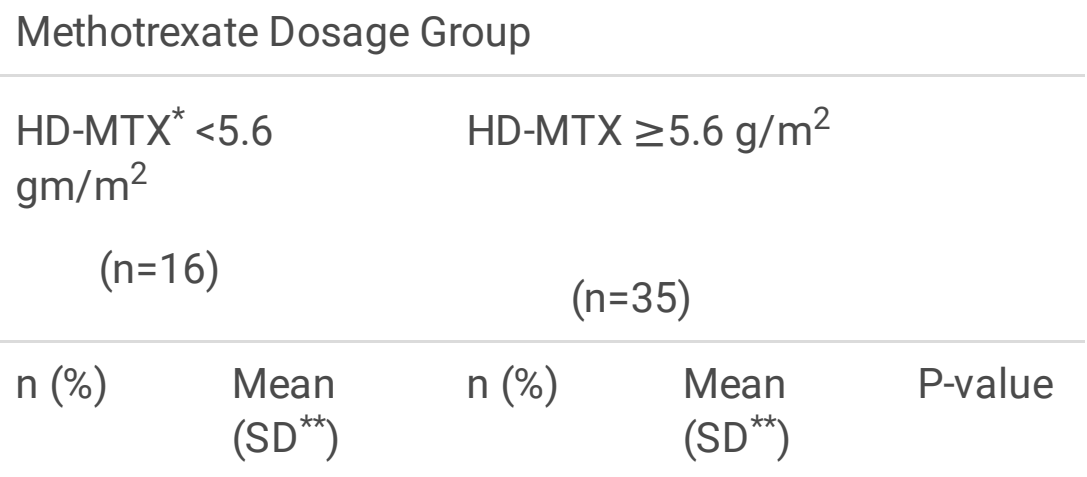

Gender

0.203

$\begin{array}{lll}\text { Female } & 8 & 11 \\ & (50.0 \%) & (31.4 \%) \\ \text { Male } & 8 & 24 \\ & (50.0 \%) & (68.6 \%)\end{array}$

Race

\begin{tabular}{lll}
\hline White & $\begin{array}{l}15 \\
(93.7 \%)\end{array}$ & 32 \\
& $(91.4 \%)$ \\
\hline African American & $1(6.3 \%)$ & $3(8.6 \%)$ \\
\hline
\end{tabular}

Age at time of Diagnosis

$73(7)$

$56(14)$

$<0.001$

Method of

Diagnosis

\begin{tabular}{lll}
\hline Brain Biopsy & 13 & 30 \\
& $(81.3 \%)$ & $(85.7 \%)$ \\
\hline CSF & $0(0.0 \%)$ & 5 \\
& & $(14.3 \%)$ \\
\hline Both & 3 & $0(0.0 \%)$ \\
& $(18.8 \%)$ &
\end{tabular}

Induction

Regimen

\begin{tabular}{|c|c|c|c|}
\hline Methotrexate Only & $\begin{array}{l}5 \\
(31.3 \%)\end{array}$ & $\begin{array}{l}9 \\
(25.7 \%)\end{array}$ & 0.742 \\
\hline $\begin{array}{l}\text { Methotrexate plus } \\
\text { Rituximab }\end{array}$ & $\begin{array}{l}11 \\
(68.8 \%)\end{array}$ & $\begin{array}{l}26 \\
(74.3 \%)\end{array}$ & \\
\hline ate Dose & & & $<0.001$ \\
\hline
\end{tabular}

Average Methotrexate Dose

*HD-MTX = High-dose Methotrexate

${ }^{*}$ SD $=$ Standard Deviation 
Table 2. COX Proportional Hazard Regression Analysis

\begin{tabular}{|c|c|c|c|c|c|}
\hline Model & Predictors & $\begin{array}{l}\text { Test } p- \\
\text { value }\end{array}$ & B & $\begin{array}{l}\text { Hazard Ratio (HR) } \\
{[95 \% \mathrm{Cl}]}\end{array}$ & $\begin{array}{l}\text { Predictor } p- \\
\text { value }\end{array}$ \\
\hline 1 & Age at diagnosis & 0.006 & 0.051 & $\begin{array}{l}1.053[1.016 \\
1.092]\end{array}$ & 0.006 \\
\hline 2 & Induction Regimen & 0.994 & -0.004 & $\begin{array}{l}0.996[0.398 \\
2.493]\end{array}$ & 0.994 \\
\hline 3 & HD-MTX Dosage Groups & 0.022 & -1.010 & $\begin{array}{l}0.364[0.154 \\
0.863]\end{array}$ & 0.022 \\
\hline 4 & $\begin{array}{l}\text { Average HD-MTX } \\
\text { dosage }\end{array}$ & 0.002 & -0.386 & $\begin{array}{l}0.680[0.530 \\
0.872]\end{array}$ & 0.002 \\
\hline 5 & $\begin{array}{l}\text { Age at diagnosis } \\
+ \\
\text { Induction Regimen }\end{array}$ & 0.019 & $\begin{array}{l}0.053 \\
0.298\end{array}$ & $\begin{array}{l}1.055[1.016, \\
1.095] \\
1.347[0.507 \\
3.581]\end{array}$ & $\begin{array}{l}0.005 \\
0.550\end{array}$ \\
\hline 6 & $\begin{array}{l}\text { Age at diagnosis } \\
+ \\
\begin{array}{l}\text { Average HD-MTX } \\
\text { dosage }\end{array}\end{array}$ & 0.016 & $\begin{array}{r}0.044 \\
-0.331\end{array}$ & $\begin{array}{l}1.045[1.002, \\
1.090] \\
0.719[0.262 \\
1.972]\end{array}$ & $\begin{array}{l}0.039 \\
0.521\end{array}$ \\
\hline 7 & $\begin{array}{l}\text { Age at diagnosis } \\
+ \\
\text { Average HD-MTX } \\
\text { dosage }\end{array}$ & 0.006 & $\begin{array}{r}0.034 \\
-0.226\end{array}$ & $\begin{array}{l}1.035[0.992, \\
1.088] \\
0.797[0.584 \\
1.088]\end{array}$ & $\begin{array}{l}0.114 \\
0.153\end{array}$ \\
\hline
\end{tabular}

Figures 

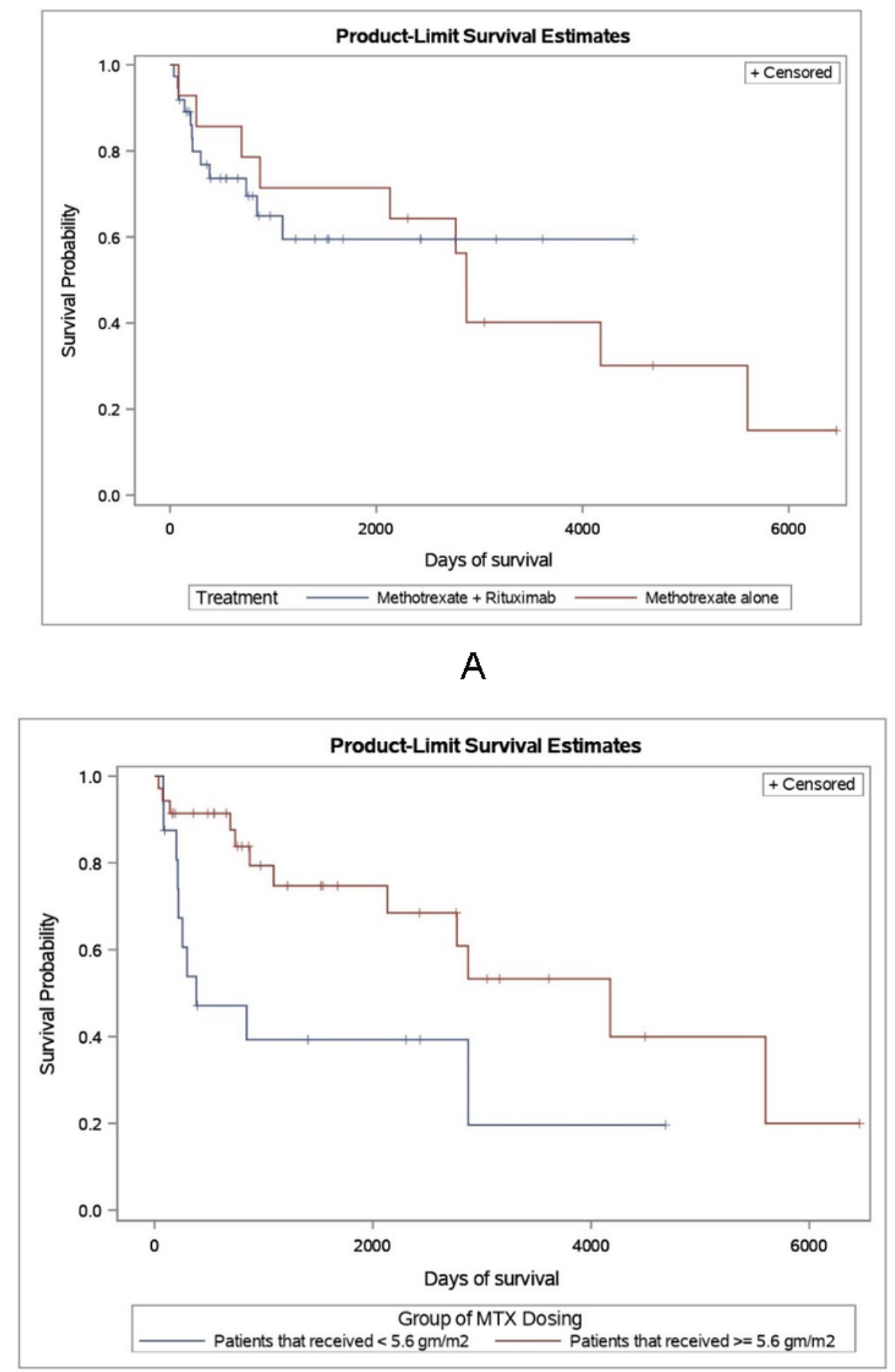

B

\section{Figure 1}

A Kaplan Meier Survival Plot of Treatment (Induction) Regimen

Kaplan-meier survival plot of treatment (induction) regimen showing no statistically significant difference in overall survival was found between PCNSL patients who underwent induction chemotherapy with HDMTX alone (Blue line) as compared to patients who had received HD-MTX plus Rituximab (Red line). 
B Kaplan Meier Survival Plot of MTX Dosage groups

Kaplan-meier survival plot of methotrexate dosages depicting favorable overall survival of patients' group within the upper half of HD-MTX spectrum (i.e, received MTX dosages $\geq 5.6 \mathrm{~g} / \mathrm{m} 2$ ) over their counterparts who were treated with dosages within the lower half of the spectrum (i.e. $<5.6 \mathrm{~g} / \mathrm{m} 2$ ).

\section{Supplementary Files}

This is a list of supplementary files associated with this preprint. Click to download.

- S.Table111821RA02.docx 